\title{
Editorial
}

\section{Self-induced autonomic dysreflexia ('boosting') practised by some tetraplegic athletes to enhance their athletic performance}

Over the decades, sport for the disabled has become increasingly popular and, as for sport for the able bodied, sport for the disabled requires to have agreed rules enforced by those who are responsible for the management and organisation of the various sporting events.

The advantages of sport for the disabled include recreational, sociological, rehabilitative and psychological; and although sport is fun, competitive sport can become more serious involving arduous training. Such real interest and training will lead up to participation in sporting events with the aim to win-for one's self, one's team, one's country: 'going for gold!' Special skills are acquired and, as for sport for the able bodied, excellent facilities, organisation and equipment are necessary. It is in this context that at times certain problems may arise such as 'doping', , 2 which includes the use of certain stimulants to improve athletic performance. Doping is prohibited (the International Olympic Games Committee 1988) and this is also the case for those participating in athletic sports for physically disabled sportspersons, as is set out in The International Paralympic Committee Handbook. ${ }^{3}$

The very interesting article published in this issue of Paraplegia (pages 292-299) by Wheeler et al on 'Testosterone, cortisol and catecholamine responses to exercise stress and autonomic dysreflexia in elite quadriplegic athletes', draws our attention to a previous article by Burnham et al on 'International induction of autonomic dysreflexia among quadriplegic athletes for performance enhancement, efficacy, safety and mechanisms of action'. ${ }^{4}$ The article by Wheeler et al refers to special laboratory studies which were carried out on the same eight athletes referred to by Burnham et al. These latter authors coined the term 'boosting' for the self-production of autonomic dysreflexia and said that, so far, there were only anecdotal reports on 'the technique' but it appeared that the practice has become common in several countries for quadriplegic (tetraplegic) wheelchair athletes.

There would appear to be medical, moral and ethical aspects of boosting that warrant attention.

The eight 'elite quadriplegic athletes' were most carefully studied by a questionnaire, performance tests, a maximal aerobic power test, a simulated $7.5 \mathrm{~km}$ road race and by post-performance assessments. Then, a statistical analysis was carried out on the differences between boosted and unboosted race time, cardiac output, pulmonary function and muscle twitch parameters. The main findings were that seven of the eight athletes boosted by overdistending their bladders, and one by sitting in his racing chair for 1-2 hours prior to the race. The efficacy of boosting was a resulting significant decrease in race time with a mean improvement of $9.7 \%(p<0.05)$ in race performance. The safety or otherwise of boosting was studied by estimating the blood pressure (BP) and the body temperature responses; $192 \mathrm{BP}$ recordings were taken, 13 were moderately elevated (systolic 160-200; diastolic 105-115); two had marked hypertension (systolic over 200; diastolic over 115). The emergency protocol described by Braddom \& Rocca was followed and was available as an emergency measure. ${ }^{5}$

The possible mechanism of the action of boosting is not fully understood. It is known that there is noradrenalin release and Burnham et al ${ }^{4}$ found that the $\mathrm{VO}_{2}$ was significantly higher $(19.8 \%)$; there were important cardiac and pulmonary effects; and oxygen utilisation was significantly higher. There were no obvious effects on metabolism or on 'the characteristics of muscle twitch'. It was felt that 'certain peripheral mechanisms' possibly accounted for the athletic benefits of boosting.

Autonomic dysreflexia can be a dangerous complication in those with a spinal cord lesion above the midthoracic level. The earliest mention of autonomic dysreflexia 
may be that of Hilton in $1860,{ }^{6}$ but the first description was by Head \& Riddoch in $1917 .{ }^{7}$ More recent accounts of the condition are worthy of consideration; and it is well known that autonomic dysreflexia can be induced by certain nociceptive stimuli distal to the level of the spinal cord injury, such as urinary bladder distension, in particular; also by prolonged perineal skin pressure, by pressure ulcers, limb muscle spasms, skeletal stimulation, anal fissure, cystitis, urinary bladder calculi and stimulation of the penis, for example, to obtain reflex erection. The threshold for autonomic dysreflexia can be lowered by repeated stimulations causing a continuous dysautonomic state, which will indeed require urgent treatment, for example, with sublingual nifedipine or intravenous phentolamine..$^{8-15}$

The main subjective features of autonomic dysreflexia include tightness in the chest; flushing and sweating above and around the spinal cord lesion; headache; gooseflesh; a pins and needles feeling in the innervated areas-neck, shoulders and sometimes the upper limbs or parts of them; shivering; and nasal stuffiness.

The main objective findings include hypertension; bradycardia; cardiac irregularities; dyspnoea; dilated pupils; peripheral vasoconstriction with piloerection; cold hands and feet; sometimes cardiac dysfunction and failure; neurological abnormalities, including cerebral haemorrhage; spasm of cerebral blood vessels; stroke; epilepsy; visual disturbances; aphasia; hyperthermia; and alterations in gastrointestinal motility. There may even be a fatal outcome. . $^{16-18}$

As Burnham et $a l^{4}$ point out, 'pre-race hydration is not unusual for any athlete'; and also 'episodic bouts for unintentional autonomic dysreflexia are not too uncommon in the everyday life of many who are quadriplegic'. These factors will require to be taken into account when self-induced, intentional boosting to cause autonomic dysreflexia is being considered and studied before, possibly at times during and also immediately following tetraplegic wheelchair sporting events. Burnham et al indeed state that boosting could be compared to the use of stimulants which have at times been used by some disabled athletes.

It should be noted that the eight 'elite quadriplegic 'vheelchair athletes' were specially chosen and specially studied by Burnham et al and indeed were also carefully monitored and supervised regarding their boosting. They were not 'ordinary athletes actually participating in a wheelchair sporting event'. These authors have clearly shown that boosting can very often produce autonomic dysreflexia, the boosting acting as an ergogenic aid. It would appear that at present only anecdotal information is available on the actual use of the technique in sporting events; how and where and by whom was the 'boosting manoeuvre' first discovered?

The real concern is the possible risks and dangers of such a procedure; also, of course, 'non-boosting' wheelchair athletes could obviously be at a disadvantage.

It is recommended that all tetraplegic (quadriplegic) sports people and their instructors, trainers and organisers and also the authorities and the governing bodies concerned with sport for the disabled should be fully aware of the technique known as 'boosting to produce autonomic dysreflexia'. Investigations and discussions are considered to be necessary and decisions taken to control the procedure; indeed it would be best if appropriate actions were taken to forbid self-induced autonomic dysreflexia in tetraplegic sports people.
Phillip Harris
Editor, Paraplegia
Honorary President of the Scottish Sports Association for the Disabled

\section{References}

1 Lombardo JA (1986) Stimulants and athletic performance: Parts 1 and 2. Phys Sports Med 14: 128-142 and 14: $85-91$. 
2 Wagner JC (1991) Enhancement of athletic performance with drugs: an overview. Sports Med 12: 250-265.

3 International Paralympic Committee (1992) The International Paralympic Committee Handbook. Section 11, Chapter 8, Item 2.1.

4 Burnham R, Wheeler G, Bhambhani et al (1994) Intentional induction of autonomic dysreflexia among quadriplegic athletes for performance enhancement: efficacy, safety and mechanisms of action. Clin J Sports Med 4: 1-10.

5 Braddon RL, Rocco JF (1991) Autonomic dysreflexia: a survey of current treatment. Am J Phys Med Rehabil 70: 234-241.

6 Hilton $\mathbf{J}$ (1860) A course of lectures on pain and the therapeutic influence of mechanical and physiological rest in accidents and surgical disease. Lancet 27 October: 401-404.

7 Head H, Riddoch G (1917) the autonomic bladder, excessive and some other reflex conditions in gross injuries of the spinal cord. Brain 40: 188-263.

8 Guttmann L, Whitteridge D (1947) Effects of bladder distension on autonomic mechanisms after spinal cord injury. Brain 70: 371-404.

9 Guttmann L, editor (1973) Spinal Cord Injuries. Blackwell Scientific Publications, Oxford: 460.

10 Mathias CJ, Christensen NJ, Corbett JL et al (1976) Plasma catecholamines during paroxysmal neurogenic hypertension in quadriplegic man. Circ Res 39: 204-208.

11 Frankel HL, Mathias CJ (1984) Manifestations and management of autonomic dysreflexia in paraplegia and tetraplegia. In: A Rossier, E Radaelli, T Radaelli, editors. Libreria Scientifica gia Ghedini s.r.l. Milan: 283-288.

12 Bloch RF (1986) Autonomic dysfunction. In: RF Bloch, editor. Management of Spinal Cord Injuries. Williams and Wilkins, Baltimore: 149-163.

13 Krum H, Louis WJ, Brown DJ et al (1992) Cardiovascular and vasoactive hormone responses to bladder distension in spinal and normal man. Paraplegia 30: 348-354.

14 Thyberg M, Ertzgaard P, Gylling M, Granerys G (1992) Blood pressure response to detrusor pressure elevation in patients with a reflex urinary bladder after a cervical or high thoracic spinal cord injury. Scand J Rehabil Med 24: 187-193.

15 Rossier AB, Ziegler WH, Duchosal PW, Meylan J (1971) Sexual function and dysreflexia. Paraplegia 9: 51-59.

16 Yarkony GM, Katz RT, Wu YC (1986) Seizures secondary to autonomic dysreflexia. Arch Phys Med Rehabil 67: 834-835.

17 Eltorai I, Kim R, Vulpe M et al (1992) Fatal cerebral haemorrhage due to autonomic dysreflexia in a tetraplegic patient: case report and review. Paraplegia 30: 355-360.

18 Illis LS (1992) Spinal cord dysfunction. In: Mathias CJ, Frankel HL, Col JD, editors. Management of Cardiovascular Abnormalities Caused by Autonomic Dysfunction in Spinal Cord Injuries. Vol. II. Oxford University Press, Oxford: 111-117. 